\title{
Semi-Empirical Oceanic Depth-Age Relationship Inferred from Bathymetric Curve
}

\author{
Tomasz Niedzielski, ${ }^{1}$ Mirosława Jurecka, ${ }^{1}$ and Piotr Migoñ ${ }^{1}$
}

\begin{abstract}
In this paper, we report on a preliminary investigation into a semi-empirical method for derivation of depth-age relationship for oceanic lithosphere. The global 30-arcsecond bathymetry data from the General Bathymetric Charts of the Oceans (GEBCO) were corrected for (1) sediment thickness using the Total Sediment Thickness of the World's Oceans and Marginal Seas and (2) isostasy. The corrected bathymetry was processed to obtain the empirical bathymetric curve, the solution computed with $50 \mathrm{~m}$ elevation bin. Subsequently, the data-based curve was approximated with the optimal polynomial model. By combining the model with a formula for derivative of area with respect to age, we obtained the approximate differential equation for depth-age relationship. We solved the equation numerically. The solution was compared with (1) depth-age relationships derived empirically using the combination of the corrected GEBCO bathymetry with digital isochrons of the oceans, (2) Parsons Sclater Model (PSM) and (3) Global Depth Heatflow model (GDH1). In the new depthage curve, three sections with specific relationships of ocean depth versus age of the crust are identified: (1) moderate increase in depth from 2500 to $5900 \mathrm{~m}$ for lithospheric ages $0-118 \mathrm{Ma}$, (2) more pronounced increase in depth from 5900 to $6700 \mathrm{~m}$ for the lithosphere 118-147 Ma old, (3) stabilization of ocean depth at 6700-6760 m for the lithosphere older than $147 \mathrm{Ma}$. The fit to empirical data as well as PSM and GDH1 models is good for the first section, but rather imperfect for the other two. Reasons for mismatches are complex and probably different for dissimilar sections of the curve.
\end{abstract}

Key words: Bathymetric curve, Sea floor topography, Depthage relationship, Geographic information system, Modelling.

\section{Introduction}

Hypsometric data, i.e. quantified information about the relationship between area and elevation, are an important source of information in geosciences at a range of spatial scales, and thus the hypsometryrelated problems have been researched for many

1 Institute of Geography and Regional Development, University of Wrocław, pl. Uniwersytecki 1, 50-137 Wrocław, Poland. E-mail: tomasz.niedzielski@uwr.edu.pl years (Murray and Huort 1912; Menard and Smith 1966). Introduced to characterize and compare drainage basins at purportedly different phases of evolution (STRAHLER 1952), it is now widely used in different contexts, from local studies to assess the impact of glaciations on valley morphology (BROCKLEHURST and WHIPPLE 2004) to global studies of Earth topography in its both terrestrial and submarine parts (HARRISON et al. 1983). The latter is shown by a global hypsometric curve which can be divided into two parts, separated by the mean sea level elevation assumed to be $0 \mathrm{~m}$. The submarine part of the curve, also known as the bathymetric curve, covers the ocean floor, and hence elevation interval from 0 to $-11,022 \mathrm{~m}$. It is characterized by a gently sloping section down to $-200 \mathrm{~m}$, coincident with shelf areas, steep descent to approximately $-2500 \mathrm{~m}$ known as the continental slope, wide plateau of abyssal plain down to approximately $-5500 \mathrm{~m}$, and final steep descent that corresponds to oceanic trench.

The bathymetric curve not only provides general characteristics of sea-floor topography averaged at the global scale. It may be also interpreted in terms of global tectonics and, specifically, in terms of lithospheric evolution. New lithosphere is produced along mid-ocean spreading ridges and then is moved away from the ridge axis as newer portions arrive at the Earth surface. Along with movement, it cools down and subsides, hence the sea floor elevation decreases with an increasing distance from spreading ridges. Since cooling process is time dependent, a general depth-age relationship may be assumed.

The first attempt to establish this relationship in a quantitative way, known as the PSM model, was by PARSONS and Sclater (1977) who proposed two different equations to describe how ocean depth changes with age of the oceanic lithosphere, each valid for specific time interval. Whilst the relationship for 
young lithosphere (up to $70 \mathrm{Ma}$ ) is described by a square-root function, it then becomes exponential. Assuming that the area of sea floor is also a function of age $(A=A(t))$ and calculating the derivative of area with respect to depth $(\mathrm{d} A / \mathrm{d} t)$, Parsons (1982) was able to obtain theoretical bathymetric curve.

This theoretical bathymetric curve was applicable to the depth interval 2500-6400 m, following model assumptions borrowed from Parsons and Sclater (1977). The former value is consistent with the mean elevation of mid-ocean ridges, the latter was named as "reference depth". Subsequent work was focused on refinement of the general depth-age relationship, using new data and different model assumptions. STEIN and STEIN (1992) offered a new model, named GDH1 (Global Depth Heatflow), which was found to fit observational data on sea floor topography better. Further discussion addressed issues such as removal of seamounts from global bathymetry data, removal of sedimentary cover, and the degree of correction for isostasy (e.g. JoHNSON and CARLSON 1992; HiLlier and Watts 2005; Crosby et al. 2006; Korenaga and Korenaga 2008; Crosby and McKenzie 2009; Hillier 2010).

In this paper, we approach the problem from a different perspective (Fig. 1). Whilst in the previous attempt PARsons (1982) aimed to arrive at the theoretical bathymetric curve, whose goodness-of-fit with real ocean depth data was a measure of model accuracy, we start from an empirical bathymetric curve which is based on high-resolution data on ocean floor topography. In the next step, we find the most adequate mathematical expression for the curve which is essential for solving our model equation numerically. We also adopt area-age relationship as proposed by PARSONS (1982) and further computation leads us to a new depth-age relationship at a global scale. Thus, our approach is essentially an inverted variation of PARSONS (1982) and followers.

Consequently, in this paper we intend: (1) to calculate an empirical bathymetric curve based on the General Bathymetric Chart of the Oceans (GEBCO) data corrected for sediment thickness following the Total Sediment Thickness of the World's Oceans and Marginal Seas (TSTWO) (Divins 2003) and consequently for isostasy, as suggested by JoHNSON and CARLSON (1992), and then (2) to use the empirical bathymetric curve along with the $\mathrm{d} A / \mathrm{d} t$ formula of
PARSONS (1982) to build a new semi-empirical model for depth-age relationship. The performance of the model in predicting the depth-age variation is compared with outputs from the previous models and with data.

The remainder of this paper is hence organized as follows. Section 2 discusses GEBCO and TSTWO data. In Sect. 3, a Python ${ }^{1}$ scripting with ArcGIS $^{2}$ geoprocessing is shown as an efficient tool for computing the empirical bathymetric curve. In addition, a new approach for calculating the depth-age relationship is described. The numerical depth-age solution is obtained through $\mathrm{R}$ programming. ${ }^{3}$ Our new semi-empirical depth-age relationship is later discussed in the light of (1) PSM and GDH1 models as well as (2) empirical depth-age relationships obtained through the combination of sediment/isostasy-corrected GEBCO bathymetry with digital isochrons of the oceans MüLLER et al. (2008).

\section{Data}

Global bathymetric data, providing a framework for bathymetric curve computation used in the paper, are part of GEBCO dataset. The GEBCO bathymetric grid belongs to a set of several publicly available digital rasters that store quantitative information about global sea-floor topography (MARKS and SMITH 2006). GEBCO has undergone a complete transformation for over 100 years, as sparse $500 \mathrm{~m}$ contours on paper charts were replaced by digital grids with ever-increasing resolution (HALl 2006). Here, the use is made of GEBCO_08 grid, the 30-arcsecond resolution global grid generated by combining qualitycontrolled ship depth soundings with interpolation between sounding points guided by satellite derived gravity data. The grid was released in September 2010 and is available to download from the British Oceanographic Data Centre (BODC).

While interpreting bathymetry and the associated bathymetric curve, the presence of sediment cover

\footnotetext{
${ }^{1}$ Python programming language, http://www.python.org/.

2 ArcMap 9.3.1 by ESRI under the ArcInfo license was used. The official ESRI webpage is: http://www.esri.com/.

${ }^{3} \mathrm{R}$ language and environment, http://www.r-project.org/.
} 
FROM DATA-BASED DEPTH-AGE RELATIONSHIP TO THEORETICAL BATHYMETRIC CURVE

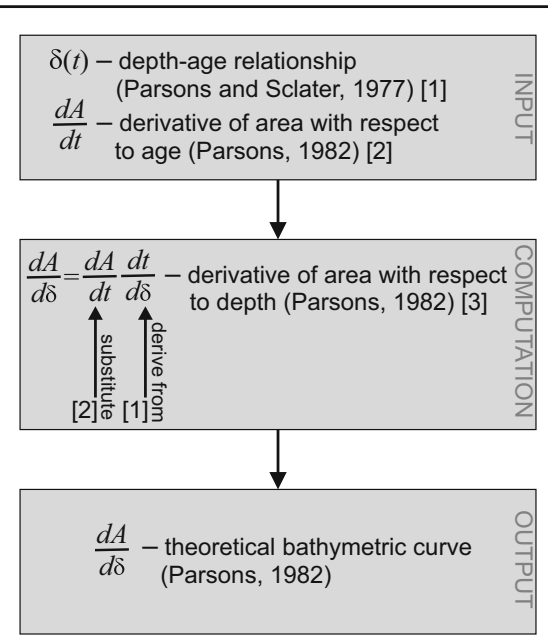

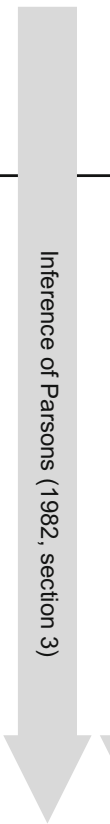

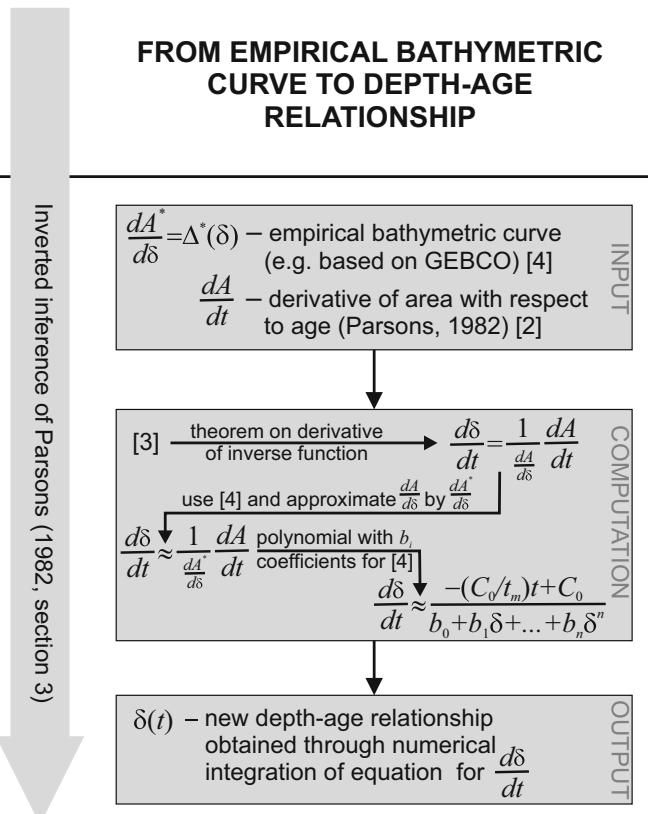

Figure 1

Sketch showing similarities and differences between the approach proposed in this paper and the procedure outlined by PARSONS (1982) in his Sect. 3

that overlays the oceanic crust has to be considered. The curve provides information about the real sea floor topography (depth = negative elevation), i.e. includes the sedimentary cover as well as submarine volcanic structures which rise above the general level of the oceanic lithosphere (HouTz et al. 1977; MoOney et al. 1998; Hillier and Watts 2005; Costello et al. 2010; Yesson et al. 2011).

Our sediment-related correction uses TSTWO which is a digital dataset with 5-arcminute grid resolution (Divins 2003). It was compiled from isopach maps, ocean drilling data and seismic reflection profiles. The data are available by courtesy of the National Geophysical Data Center (NGDC) of the National Oceanic and Atmospheric Administration (NOAA) in the USA. A note should be given on the applicability of the TSTWO gridded data, the resolution of which is coarse. HASTEROK (2013) argues that-although the considerable discrepancies between the TSTWO and site-specific observations may exceed even $40 \%$-the dataset is suitable for global investigations, and this justifies our selection of the sediment cover numerical map which, in addition, is said to be the best dataset of this type.
To calculate the depth of oceanic crust $d_{C}$, i.e. bathymetry corrected for sediment thickness and isostasy, we (1) transformed the TSTWO raster dataset so that it has a consistent spatial reference with the spatial reference of GEBCO bathymetry and (2) in a gridwise fashion applied the following model (JoHNSON and CARLSON 1992):

$$
d_{\mathrm{C}}=d_{\mathrm{G}}+\frac{\rho_{\mathrm{m}}-\rho_{\mathrm{s}}}{\rho_{\mathrm{m}}-\rho_{\mathrm{w}}} h_{\mathrm{T}}
$$

where $d_{\mathrm{G}}$ is the depth (positive) obtained from GEBCO bathymetry, $h_{\mathrm{T}}$ is the sediment thickness from TSTWO dataset, $\rho_{\mathrm{m}}$ is the mantle density, $\rho_{\mathrm{s}}$ is the sediment density, and $\rho_{\mathrm{w}}$ is the seawater density. However, the choice of density constants is not straightforward and certain compromises have to be made. Whilst we are aware that different values of these constants may be adopted, partly because each material is characterized by a range of density values, we ultimately decided to use the same densities as adopted by PARSONS and SCLATER (1977) in their classic exercise. Although the exact numbers may be disputable, this is the only way to attempt the comparison of our model and the PSM solution. Thus, we assumed the following constants: 
$\rho_{\mathrm{m}}=3330 \mathrm{~kg} \mathrm{~m}^{-3}, \quad \rho_{\mathrm{s}}=1700 \mathrm{~kg} \mathrm{~m}^{-3}, \quad \rho_{\mathrm{w}}=$ $1000 \mathrm{~kg} \mathrm{~m}^{-3}$, which are within the range of the commonly accepted ones, although tend to be at the lower end of these ranges. Indeed, sediment densities vary between 1700 and $1950 \mathrm{~kg} \mathrm{~m}^{-3}$ (SYKEs 1996), seawater density ranges from 1000 to $1070 \mathrm{~kg} \mathrm{~m}^{-3}$ due to changes in the temperature, salinity and pressure, with mean seawater density of $1032 \mathrm{~kg} \mathrm{~m}^{-3}$ (Tenzer et al. 2011), and mantle density is usually assumed to be equal to $3300 \mathrm{~kg} \mathrm{~m}^{-3}$. Our final raster dataset is limited only to the areas that are fully covered with information from GEBCO and TSTWO datasets.

To include the information about the age of the crust, we used the digital model by MüLLER et al. (2008). The age of the world's oceanic crust is stored as 2-min resolution gridded dataset which includes data from all the major ocean basins and considers back-arc basins in greater detail. They determined ages of the crust by applying linear interpolation between adjacent seafloor isochrons in the direction of spreading. The ages of the ocean floor, between the oldest identified magnetic anomalies and the continental crust, were interpolated through the estimation of the age of relevant segments of continental passive margins. Detailed grid documentation is available to reach on the NGDC website.

\section{Methods}

To compute an empirical bathymetric curve, through processing the sediment/isostasy-corrected GEBCO raster data, one has to extract information on the area of sea floor (or sediment/isostasy-corrected sea floor) for a user-defined depth bin. To accomplish this goal, Python scripting with ArcGIS geoprocessing is used here. The fitted empirical bathymetric curve serves as an input to a semi-empirical investigation that aims to derive a new model equation for depth-age relationship.

\subsection{Processing Bathymetric Data}

We produced a Python script which provides us with the opportunity to compute a hypsometric curve for the entire Earth (if input raster contains geospatial data that reveal the global coverage and full elevation range). Although a selection of elevation range depends on the user, in our experiment we choose a minimum depth of $2500 \mathrm{~m}$ and a maximum depth of $6400 \mathrm{~m}$, the numbers that, after PARSONS and SCLATER (1977), are explicitly given by PARsons (1982). Hence, we focus on a key part of a bathymetric curve, and hereinafter we call this portion of the curve as bathymetric curve.

After having parameters defined, the script starts to run three consecutive and depth-dependent operations: (1) raster reclassification, (2) conversion of reclassified raster data into feature data and (3) computation of area for all fragments of the sea floor (or sediment-corrected sea floor) extracted using reclassification. In the latter operation, continuous data are divided into classes that contain parts of sea floor (or sediment-corrected sea floor) at specific depth ranges. Once it is done, raster data are converted into feature class. The next step aims to achieve the integrated area of the sea floor (or sediment-corrected sea floor) fragments for each depth bin. In our script, it is done using zonal statistics tools in Geographic Information Systems (GIS). The results of the calculation are aggregated in the output table as two columns providing depth intervals and corresponding area information, and hence the output forms an empirical bathymetric curve.

\subsection{Relationship Between Depth and Age}

This subsection presents a new semi-empirical approach to derive a relation between depth and age of the sea floor, namely $\delta=\delta(t)$. Following Parsons and Sclater (1977) as well as Stein and Stein (1992), $\delta(t)$ is controlled by simple analytical formulas, the parameters of which are empirical. Herein, we propose an alternative approach to derive a depthage curve, and the novelty of the idea is due to a concurrent use of two input datasets: the derivative of area with respect to age (PARSONS 1982) and the GEBCO-based (and sediment/isostasy-corrected) empirical bathymetric curve. However, a key concept of our approach is based on the procedure outlined by PARSONS (1982) in his Sect. 3. We invert his inference (depth-age + area-age $\rightarrow$ theoretical bathymetric curve) to work in a opposite way (empirical 
bathymetric curve + area-age $\rightarrow$ depth-age). Our approach is graphically presented in Fig. 1, and the details of the procedure are given below.

Let us assume that $A=A(t)$ corresponds to area of sea floor as a function of age $t$. The analytical bathymetric curve is thus given by a derivative $\frac{\mathrm{d} A}{\mathrm{~d} \delta}$, as it expresses how infinitesimal area of the sea floor varies with infinitesimal depth. Note that both $A$ and $\delta$ vary with age. Hence, after taking derivative of superposition of two functions, the following condition holds (PARSONS 1982):

$$
\frac{\mathrm{d} A}{\mathrm{~d} \delta}=\frac{\mathrm{d} A}{\mathrm{~d} t} \frac{\mathrm{d} t}{\mathrm{~d} \delta} .
$$

Subsequently, we re-write the above equation and apply the theorem on derivative of inverse function to obtain the following simple formula:

$$
\frac{\mathrm{d} \delta}{\mathrm{d} t}=\frac{1}{\Delta(\delta)} \frac{\mathrm{d} A}{\mathrm{~d} t},
$$

where $\Delta(\delta)$ is the aforementioned theoretical bathymetric curve $\frac{\mathrm{d} A}{\mathrm{~d} \delta}$. By definition, the GEBCO-based empirical bathymetric curve, denoted hereinafter as $\Delta^{\star}(\delta)$, should accurately approximate its theoretical analogue $\Delta(\delta)$. Assuming this, it is possible to propose a modified semi-empirical formula for $\frac{\mathrm{d} \delta}{\mathrm{d} t}$ as:

$$
\frac{\mathrm{d} \delta}{\mathrm{d} t} \approx \frac{1}{\Delta^{\star}(\delta)} \frac{\mathrm{d} A}{\mathrm{~d} t},
$$

where, after PARSONS (1982), we have $\frac{\mathrm{d} A}{\mathrm{~d} t}=C_{0}\left(1-\frac{t}{t_{\mathrm{m}}}\right)$ for which $C_{0}$ is the constant rate of generation of new sea floor and $t_{\mathrm{m}}$ is the maximum age. To solve the above-mentioned differential equation, the GEBCOderived bathymetric curve can be approximated by the following polynomial model:

$$
\Delta^{\star}(\delta) \approx \sum_{i=0}^{n} b_{i} \delta^{i},
$$

where $b_{i}, i=0, \ldots, n$, are coefficients and $n$ corresponds to degree of a given polynomial. After substituting Eq. (5) and the expression for $\frac{\mathrm{d} A}{\mathrm{~d} t}$ to Eq. (4), we obtain the approximate formula:

$$
\frac{\mathrm{d} \delta}{\mathrm{d} t} \approx \frac{-\frac{C_{0}}{t_{\mathrm{m}}} t+C_{0}}{\sum_{i=0}^{n} b_{i} \delta^{i}} .
$$

When a specific polynomial quantifying a semi-empirical bathymetric curve $\Delta^{\star}(\delta)$ is known, and if the approximation is substituted by equality, one may find a numerical solution to Eq. (6).

To estimate an analytical approximation of $\Delta^{\star}(\delta)$, global fit should be performed. The estimation may be carried out using the ordinary least-squares method.

\section{Results and Discussion}

Following PARSONS (1982), the minimum depth of $2500 \mathrm{~m}$ is chosen, and-as mentioned above-this elevation corresponds to the average depth of oceanic ridges. A maximum depth under study, namely 6400 $\mathrm{m}$, corresponds to reference depth of PARSONS and Sclater (1977) and Parsons (1982), often denoted as $d_{\mathrm{r}}$. Reference depth $d_{\mathrm{r}}$, along with the thickness of oceanic crust and the thickness of continental crust, remains a dominant element that forms an expression for continental freeboard (GALER 1991; GALER and Mezger 1998), and may be interpreted as a long-term ocean basin ultimate depth.

Figure 2 presents the reclassified uncorrected GEBCO bathymetry with the maximum and minimum depth bins, while Fig. 3 shows bathymetry corrected for sediment thickness and isostasy. The difference between coarse $(500 \mathrm{~m})$ and fine $(50 \mathrm{~m})$ depth sampling is noticeable in small cartographic scale (Figs. 2a, b, 3a, b), and becomes more pronounced for larger scales as it is shown for the Northern Indian Ocean (Figs. 2c, d, 3c, d). Hereinafter, we use only the corrected bathymetric data with the $50 \mathrm{~m}$ depth bin.

Following PARSONS (1982), the bathymetric curves presented in this paper are expressed in $10^{4} \mathrm{~km}^{2} / \mathrm{m}$, as total areas are divided by corresponding depth intervals. Figure 4 presents two empirical bathymetric curves, for uncorrected (full line) and sediment/ isostasty-corrected (dashed line) bathymetry. The subsequent analysis is limited to the sediment/isostasy-corrected bathymetric curve.

For uncorrected bathymetry, the distribution is bimodal (see also SMith and SANDwell 1997), with the maximum area for depths at 4300-4350 $\mathrm{m}$ and the second modal value at $4950-5000 \mathrm{~m}$. This setup reverses when the sediment/isostasy-corrected bathymetric curve is considered. For such a corrected 

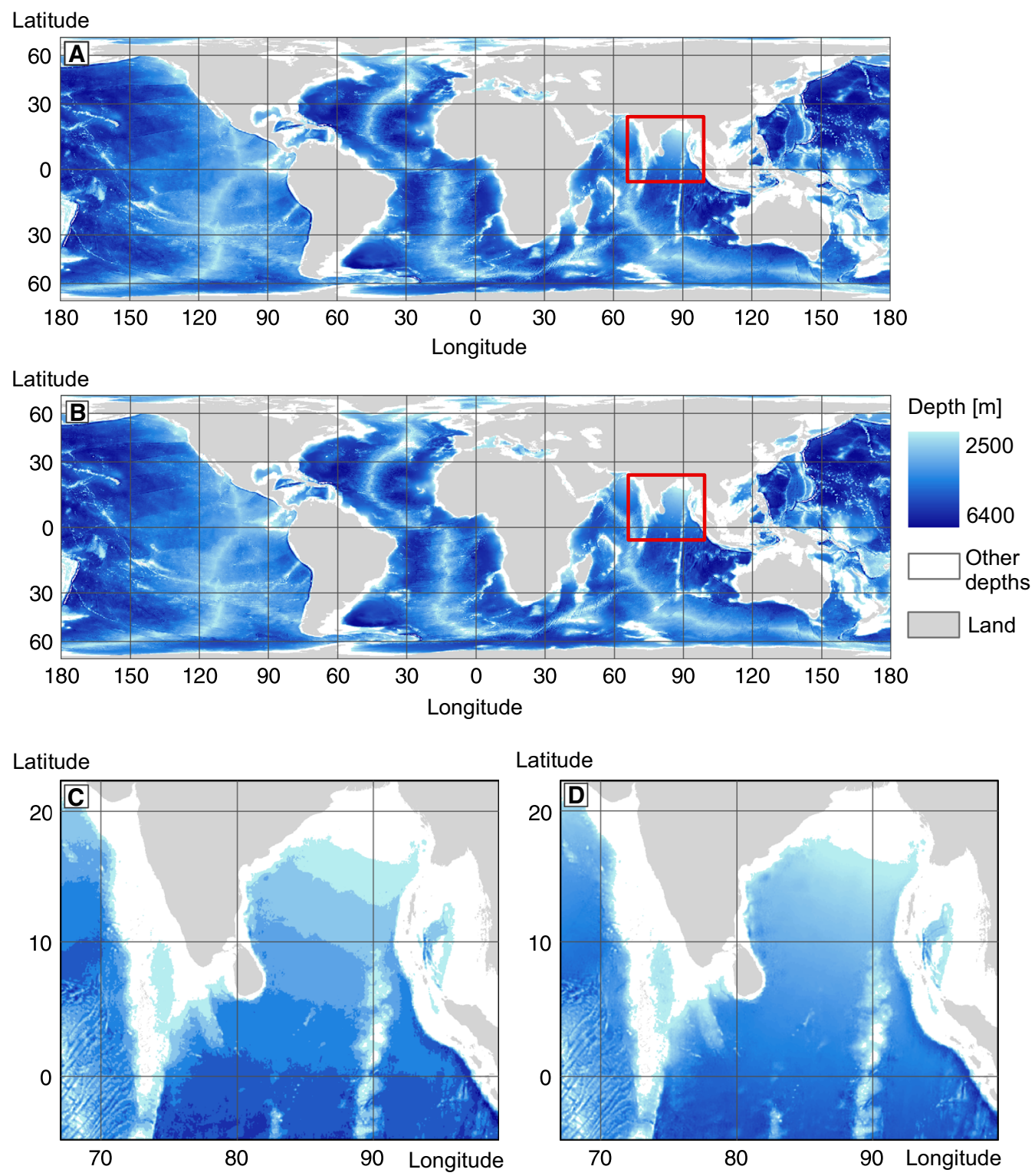

Figure 2

Reclassified GEBCO bathymetry between depths of 2500 and 6400 m; entire Earth with depth interval of 500 m (a), entire Earth with depth interval of $50 \mathrm{~m} \mathrm{(b)}$, the Northern Indian Ocean with depth interval of $500 \mathrm{~m}$ (c) and the Northern Indian Ocean with depth interval of $50 \mathrm{~m}$ (d)

bathymetry, the distribution is also bimodal, but the first modal value is lower than the second one and occurs at $4800-4850 \mathrm{~m}$, whereas the second modal value corresponds to the maximum and is attained at 5300-5350 m. Such a swap of modes, when uncorrected and corrected bathymetry datasets are compared, was earlier presented by SMITH and SANDWELl (1997).
Knowing the empirical bathymetric curve, it is possible to fit polynomial models along the lines of Eq. (5). We need a functional form of the bathymetric curve to subsequently use it in our expression for the derivative of depth with respect to age, which later is numerically integrated. Figure 5a shows the ultimate empirical bathymetric curve with 20 polynomial models of degrees ranging from 1 to 20 . One of the 

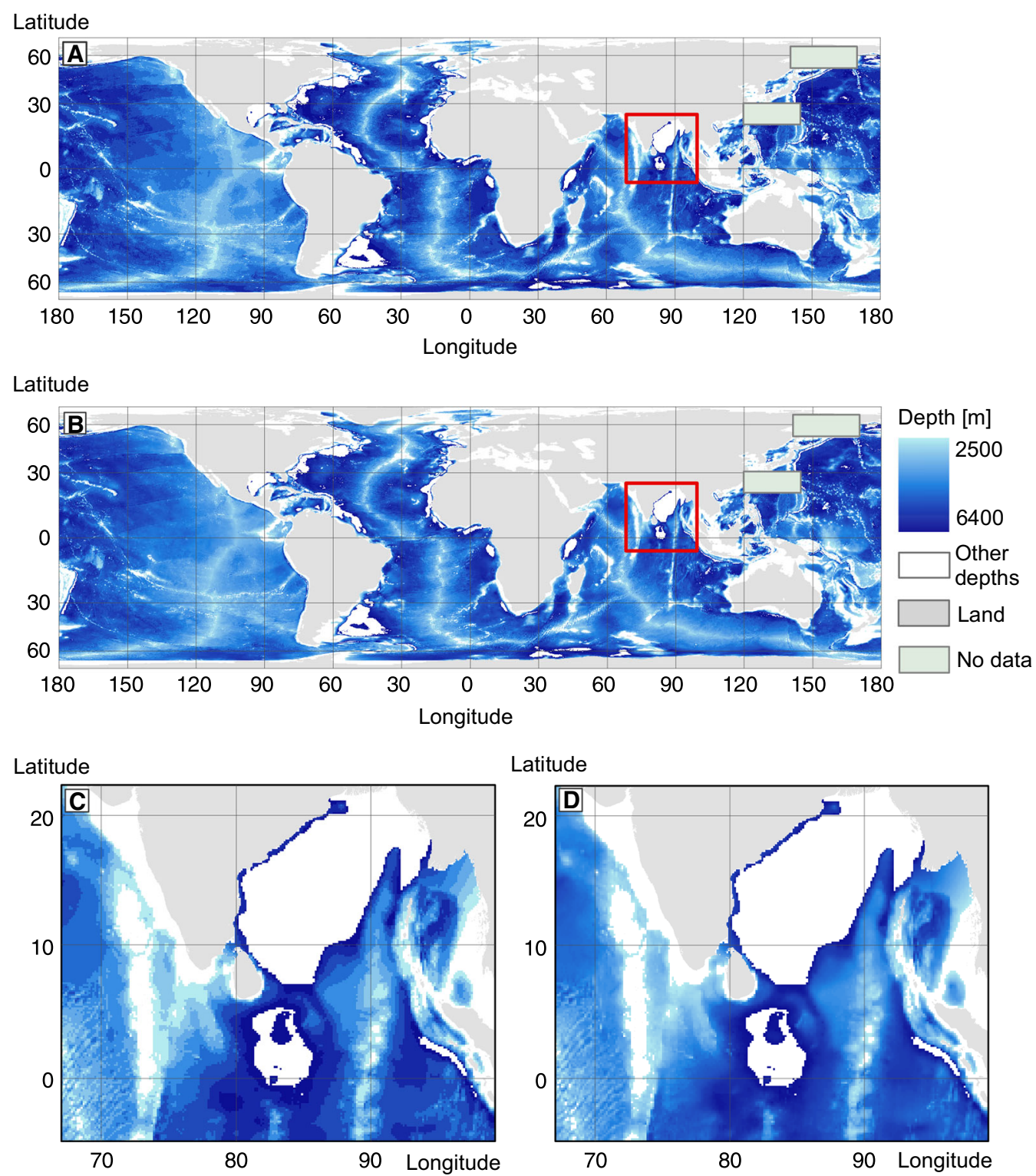

Latitude

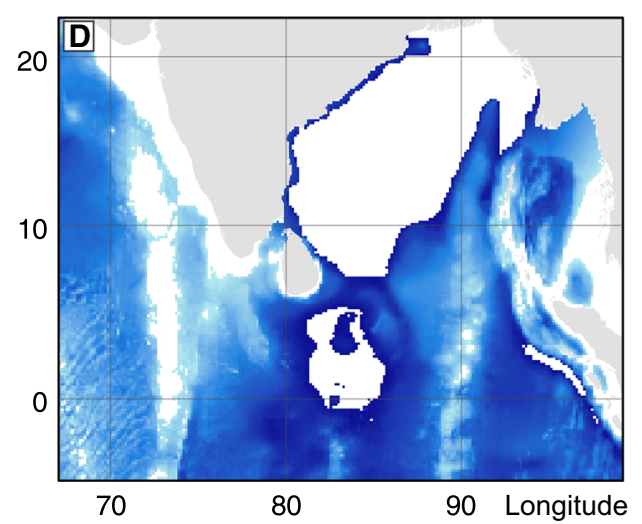

Figure 3

Reclassified sediment/isostasy-corrected GEBCO bathymetry between depths of 2500 and $6400 \mathrm{~m}$; entire Earth with depth interval of $00 \mathrm{~m}$ (a), entire Earth with depth interval of $50 \mathrm{~m}(\mathbf{b})$, the Northern Indian Ocean with depth interval of $500 \mathrm{~m}$ (c) and the Northern Indian Ocean with depth interval of $50 \mathrm{~m}(\mathbf{d})$

curves is assumed to be optimal, i.e. the one that corresponds to polynomial of degree 16 . The optimal model is selected using the Akaike Information Criterion (AIC) (AKAIKE 1971). Indeed, AIC is minimized for the polynomial model of degree 16 (Fig. 5b). Although many of the coefficients $b_{i}$ are equal to zero for $i \geq 10$ and the first local AIC minimum is attained for the degree of 9 , we used degree 16 following the overall minimization of AIC for $i=1, \ldots, 20$. Even though the two local maxima of bathymetric curve are not entirely captured by the polynomial, the fit allows to model much of the variability of the ultimate curve. The coefficients of the polynomial are juxtaposed in Table 1 . 


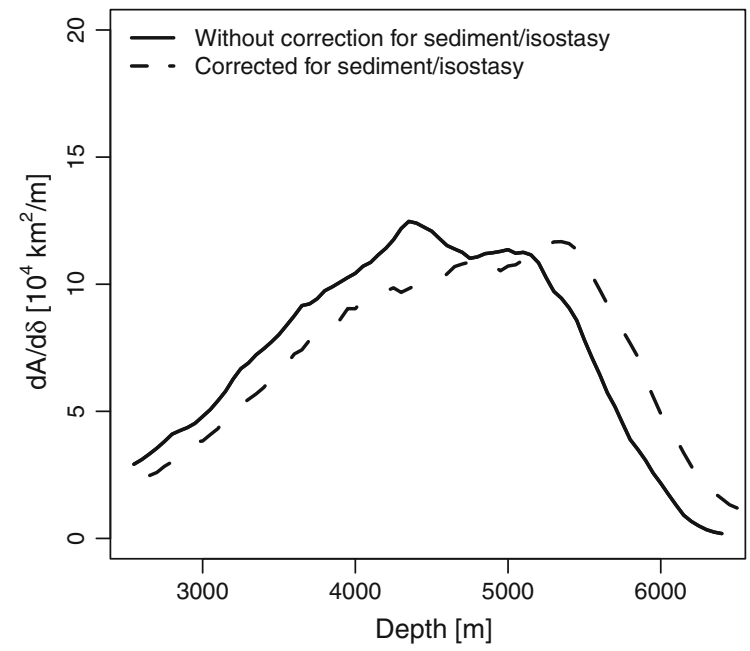

Figure 4

Empirical bathymetric curves derived from GEBCO bathymetry for $50 \mathrm{~m}$ depth bin; uncorrected solution is expressed by a full line and sediment-corrected solution is plotted using a dashed line

The function expressed as Eq. (6) is subsequently numerically integrated to obtain a relationship between depth and age, namely $\delta(t)$. Figure 6a shows the results of the integration carried out with the boundary condition set as $\delta(0)=2500$ which-following PARSONS 1982-is the mean depth of oceanic ridges at present, with $C_{0}=3.45 \mathrm{~km}^{2} /$ year and $t_{m}=$ $18010^{6}$ years. For integration, all constants and variables have been converted into SI units.

It is worth addressing the issue of the rates of plate creation and destruction. As shown above, we assume that the rate of generation of the new sea floor, i.e. $C_{0}$, is constant over time. We do so following the area-age model of PARSONS (1982), and after Rowley (2002) who confirmed the steady rate. The latter author, using the digital isochrons of MüLlER et al. (1997), proved that (1) the rate in question is indeed constant and its value may be approximated as $3.4 \mathrm{~km}^{2} /$ year and (2) PARSONS (1982) approach is valid. However, the problem of $C_{0}$ is still under scrutiny, as a few authors argue that the rate of plate creation/destruction varies in time and reveals nonlinear changes (Miller et al. 2005; CoLTICE et al. 2012). Following PARsons (1982) and Rowley (2002) we assume constant $C_{0}$; however, our model can be modified to account for nonlinear changes in the area-age relationship.
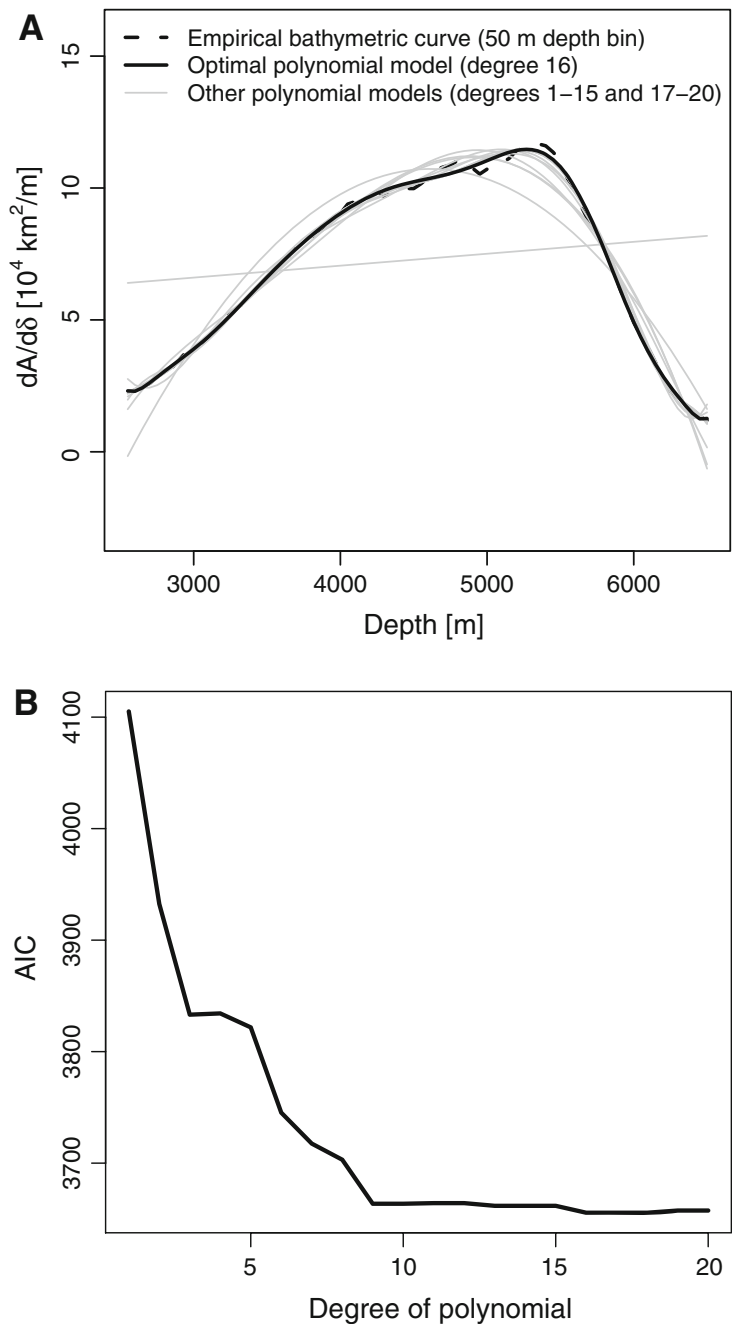

Figure 5

Ultimate solution of empirical sediment-corrected bathymetric curve derived for $50 \mathrm{~m}$ depth interval (black dashed line) and its polynomial models (gray lines), with optimal solution (black full line) (a), Akaike Information Criterion (AIC) computed for polynomial models as a function of degree (b)

Although an increase in ocean depth is continuous across the adopted age range, changes are nonlinear. The graph can be divided into three parts. In the first one, within the age interval $0-118 \mathrm{Ma}$, the mean ocean depth increases steadily to approximately 5900 $\mathrm{m}$. Elevation decline is more pronounced for the oceanic crust older than $118 \mathrm{Ma}$, and reaches a breakpoint of $6700 \mathrm{~m}$ at approximately $147 \mathrm{Ma}$. Subsequently, for ages 147-180 Ma, depth stabilizes at $6700-6760 \mathrm{~m}$ (note that the reference depth of $6400 \mathrm{~m}$ is exceeded). 
Table 1

Coefficients of the optimal polynomial, with depth (in metres) as parameter, that approximates the ultimate bathymetric curve for 50 $m$ depth bins

\begin{tabular}{ll}
\hline Symbol of coefficient & Value of coefficient \\
\hline$b_{0}$ & $8.959437143220060999899 \times 10^{15}$ \\
$b_{1}$ & $-2.549173168801770703170 \times 10^{13}$ \\
$b_{2}$ & $3.263336583828357696617 \times 10^{10}$ \\
$b_{3}$ & $-2.477696228451177477836 \times 10^{7}$ \\
$b_{4}$ & $1.236823110887738403165 \times 10^{4}$ \\
$b_{5}$ & -4.244481486466133546287 \\
$b_{6}$ & $1.013677324218681136819 \times 10^{-3}$ \\
$b_{7}$ & $-1.656192801982570400295 \times 10^{-7}$ \\
$b_{8}$ & $1.737303292081741213412 \times 10^{-11}$ \\
$b_{9}$ & $-9.553605395905479679211 \times 10^{-16}$ \\
$b_{10}$ & 0 \\
$b_{11}$ & $2.523971785884253113668 \times 10^{-24}$ \\
$b_{12}$ & 0 \\
$b_{13}$ & $-8.097405750305437945914 \times 10^{-33}$ \\
$b_{14}$ & 0 \\
$b_{15}$ & 0 \\
$b_{16}$ & $1.212650903911004771898 \times 10^{-45}$ \\
\hline
\end{tabular}

The big number of fractional digits in coefficients is required to produce accurate simulations of bathymetric curve using the polynomial model

The semi-empirical depth-age curve computed in this paper may be compared with other curves, produced from various data and based on various assumptions (Goutorbe and HiLlier 2013). For simplicity, we compare our curve with a selection of others, including those reflecting PSM and GDH1 models as well as the sediment/isostasy-corrected GEBCO with digital isochrons of the oceans proposed by MülLER et al. (2008), denoted GEBCO-M. All these use the same depth interval 2500-6400 m. The curve derived in this paper agrees particularly well with fully empirical depth-age relationship from GEBCO-M. However, this holds only for the first of the aforementioned intervals, i.e. ranging from 0 to $118 \mathrm{Ma}$ and corresponding to the steady increase of mean ocean depth to approximately $5900 \mathrm{~m}$ (Fig. 6a).

In addition, Fig. 6a compares the depth-age relationship obtained from numerical integration of the equation proposed in this paper, with two other models of this relationship. The PSM model, originally presented by PARSONS and SCLATER (1977), is split into two parts, following two different, partly overlapping regimes of fast cooling and slow cooling respectively. In general, for most of the age range considered here, our curve shows shallower ocean depth than the other models predict. Only in its final part, the relationship reverses and the depth for given age is greater than model predictions. With respect to the PSM model, the reversal occurs at age of $118 \mathrm{Ma}$, while it is placed at $90 \mathrm{Ma}$ if comparison with GDH1 model is attempted.

The magnitude of mismatch between these different curves is shown in Fig. 6b. Hereinafter, we write "positive mismatch" if elevation computed using our approach is greater than the elevation predicted by empirical data or models (negative depth difference in Fig. 6b), whereas "negative mismatch" corresponds to a reverse situation (positive depth difference in Fig. 6b).

Reasons for the observed mismatches are likely complex. A partial explanation may reside in input data used in the different exercises referred to. In addition, while arbitrary truncating the global ocean depth data at $2500 \mathrm{~m}$ we also included the deepest parts of the continental slope, and not only mid-ocean ridges and abyssal plains. Thus, the shallow depth area is somehow overrepresented.

Second, our depth-age curve is obtained semiempirically. The physical background is provided by: (1) PARsons (1982) model for derivative of sea floor area with respect to age (two constants are needed: $C_{0}$, $t_{\mathrm{m}}$ ), (2) accurate present-day sediment/isostasy-corrected GEBCO bathymetry truncated at $d_{0}$ and $d_{\mathrm{r}}$, (3) present-day mean depth of oceanic ridges $d_{0}$. Hence, our solution uses physical models and data, and its empirical character is due to polynomial modelling of bathymetric curve and the subsequent numerical integration of the governing equation. In contrast, PSM and GDH1 models utilize wider sets of parameters and are derived using different methods. For instance, except from $d_{0}$ and $d_{r}$, PSM formulae use $a=350 \mathrm{~m} /(\mathrm{Ma})^{1 / 2}, b=3200 \mathrm{~m}$ and $\tau=62.8 \mathrm{Ma}$. Then, the corrections for sediment thickness and isostasy were applied using model solutions, with the isostatic correction being done according to PARSONS and Sclater (1977) and Parsons (1982), and the sediment correction being based on the recent TSTWO.

The negative mismatch in the final part of our depth-age curve likely results from its semi-empirical character. Both PSM and GDH1 models predict how the ocean depth will change with age, as dictated 

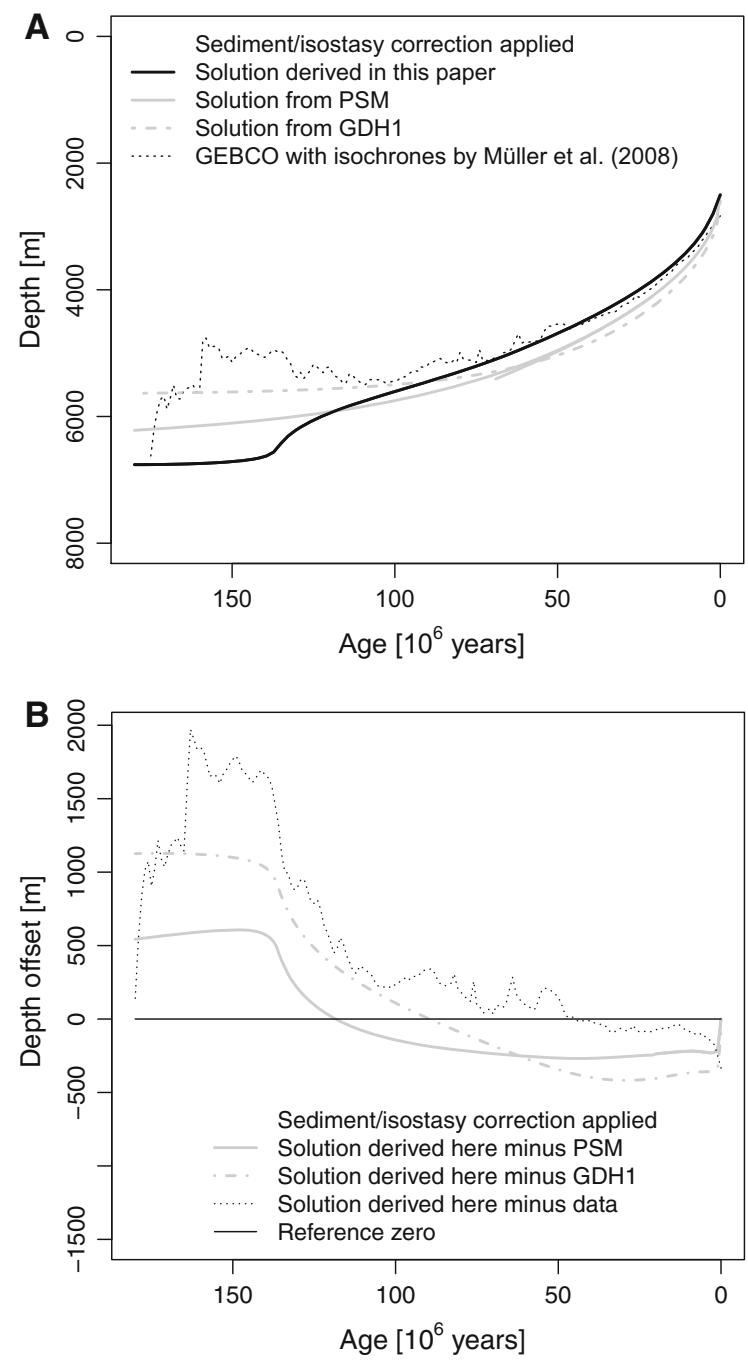

Figure 6

Relationship between age and depth of the oceanic crust derived in this paper (black full line) against a background of: PSM ( gray full line) and GDH1 models (gray dashed line), empirical depth-age curve computed from sediment/isostasy-corrected GEBCO combined with isochrones by MüLLER et al. (2008) (black dotted line) (a), differences between the solution derived in this paper and four models/datasets considered above (b). Abbreviations are explained in Sect. 1

by the adopted physical formulae inherent in the plate model. They predict that the ultimate depth of the new oceanic lithosphere is allowed to cool indefinitely. But this is not everywhere the case and different real-world situations are captured by truncation of the global bathymetric curve at $6400 \mathrm{~m}$. They include large oceanic basins with very old lithosphere that essentially attained its predicted thickness due to long-term cooling, hence depth, as well as oceanic trenches where relatively young lithosphere $(<50 \mathrm{Ma})$ is already being subducted. In the latter situations, young lithosphere can be found at significantly higher depths than physically based models predict.

To confirm that the above-mentioned new depthage relationship is not a consequence of coincidence, we planned a simple numerical experiment. Instead of taking the GEBCO-based bathymetric curve, we simulated three artificial curves and assumed they approximate $\Delta^{\star}(\delta)$ (Fig. 7a). The first one is a triangular curve, the integral of which is identical with the total area calculated from the GEBCO-based bathymetric curve. The similar condition of equal areas below the curve was fulfilled in the case of the second, rectangular curve. It assumes a uniform distribution of the areas as a function of depth. The third curve is also rectangular; however, it is entirely unrealistic as its integral varies largely from the total area estimated from the GEBCO-based solution.

Figure $7 \mathrm{~b}$ shows that the model proposed in this paper fits well with the depth-age data for ages ranging from 0 to $118 \mathrm{Ma}$. The same model, however, fed by artificial curves described in the previous paragraph (Fig. 7a), produces worse results. Indeed, the solution based on the unrealistic curve leads to an unrealistic depth-age curve, with depth reaching 10,000 $\mathrm{m}$ at 118 Ma. This clearly shows that our approach is vulnerable to input bathymetric curve and, thus, our depth-age model is not a result of a numerical artifact. Similar exercises, based on the above-mentioned artificial curves which are more realistic and reveal the same total areas (when area-depth curve is integrated over time), support this finding. Indeed, both triangular and rectangular area-depth functions with the same total area as the true bathymetric curve lead to more reasonable depth-age relationships; however, their fit to the observed data is still worse than in the case of the model proposed in this paper.

\section{Conclusions}

The empirical bathymetric curve, based on the sediment/isostasy-corrected GEBCO with $50 \mathrm{~m}$ depth bin, revealed two local maxima, and their shapes were in 

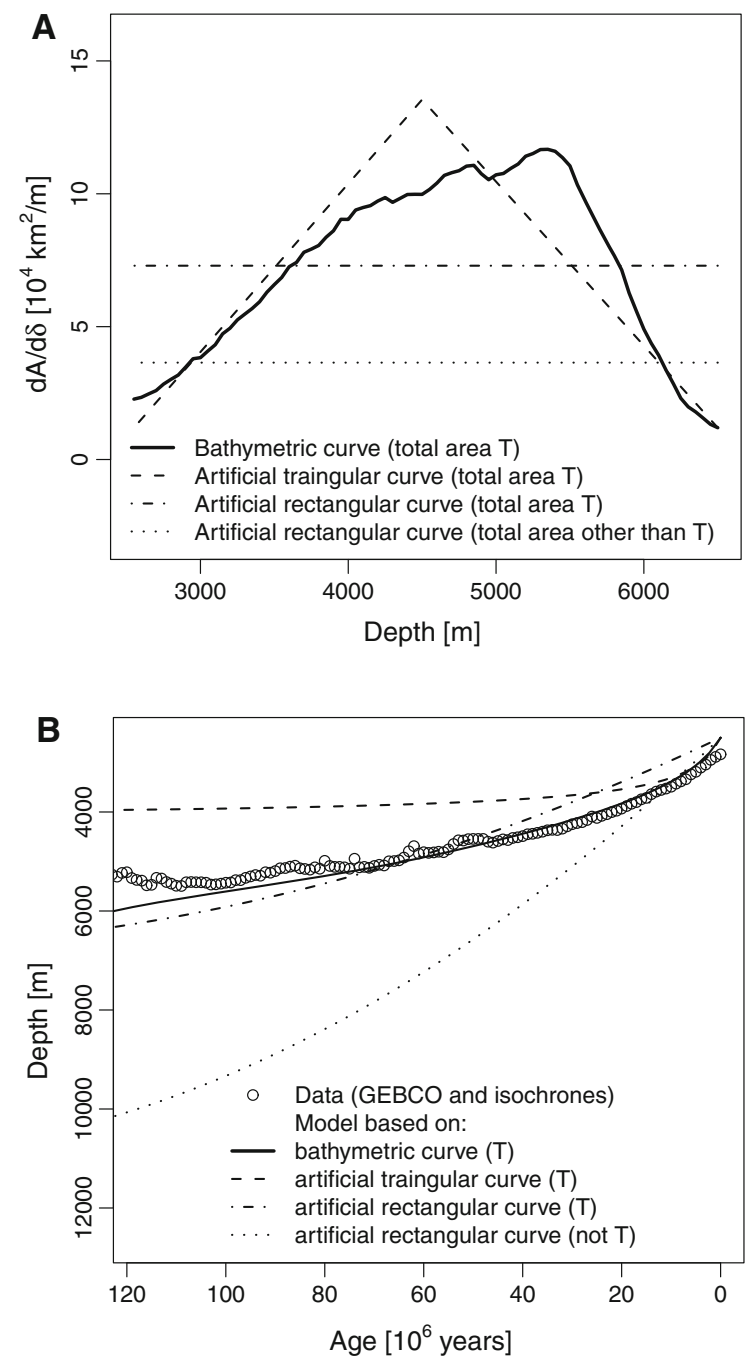

Figure 7

Experimental application of Eq. (6) with the use of true bathymetric curve (applied in this paper) and three artificial curves (two with the same total area $\mathrm{T}$ as the true bathymetric curve, and one entirely unrealistic with area under the graph different from $\mathrm{T}$ ): the curves (a), depth-age relationships based on the above-mentioned formula and curves, superimposed on the depth-age data from MüLLER et al. (2008) (b)

agreement with those presented elsewhere and widely accepted. That specific curve was subsequently processed, and the polynomial of degree 16 was found to serve as its reasonable model. The model equation was subsequently substituted to a formula that estimates the rate of mean ocean depth variation. The differential equation was solved numerically. The novelty of our approach resides in the concept of inversing the procedure outlined by PARsONs (1982, section 3) who began with depth-age and area-age relationships to produce a theoretical bathymetric curve. Our approach starts from an empirical bathymetric curve and area-age relationship to derive a new depth-age curve.

The new depth-age curve was generated for ages between 0 and 180 Ma. Three ranges of specific relationships of ocean depth versus age of the crust are identified: (1) moderate increase in depth from 2500 to $5900 \mathrm{~m}$ for lithospheric ages $0-118 \mathrm{Ma}$, (2) more pronounced increase in depth from 5900 to $6700 \mathrm{~m}$ for the lithosphere 118-147 Ma old, (3) stabilization of ocean depth at $6700-6760 \mathrm{~m}$ for the lithosphere older than $147 \mathrm{Ma}$.

The model solution presented here agrees relatively well with the previous models proposed by PARSONS and Sclater (1977) and Stein and Stein (1992). Minor discrepancy and positive mismatch for young and middle-age lithosphere (until $118 \mathrm{Ma}$ ) can be attributed to the more accurate bathymetric data we could use as model parameters. The divergence between model curves for the depth-age relationship for the older lithosphere, and particularly the rather sharp drop for the 118-147 Ma age range, absent in previous solutions, may have complex reasons. Apart from the influence of the data quality (higher resolution GEBCO model), we suggest that the effects of subduction into oceanic trenches are captured here. Subduction is a process which, in specific circumstances, does not allow the oceanic crust to cool long enough to attain the thickness (and depth) predicted by physically based models. The results reported in this paper are preliminary, and hence further investigation into the semiempirical depth-age relationship is needed.

\section{Acknowledgments}

This work is supported through the Homing Plus Grant of the Foundation for Polish Science, Contract No. Homing Plus_2011-3/8, founded by the European Regional Development Fund and the Innovative Economy Programme. The computations are performed using ArcGIS geoprocessor supported by Python scripting and R language equipped with "polynom" and "deSolve" packages. Last but not least, we thank Bartłomiej Miziński for double checking our computational results based on numerical integration. 
Open Access This article is distributed under the terms of the Creative Commons Attribution 4.0 International License (http:// creativecommons.org/licenses/by/4.0/), which permits unrestricted use, distribution, and reproduction in any medium, provided you give appropriate credit to the original author(s) and the source, provide a link to the Creative Commons license, and indicate if changes were made.

\section{REFERENCES}

AKAIKE, H. (1971), Autoregressive model fitting for control, Annals of the Institute of Statistical Mathematics 23, 163-180.

Brocklehurst, S.H., and Whipple, K.X. (2004), Hypsometry of glaciated landscapes, Earth Surface Processes and Landforms 29, 907-926.

Coltice, N., Rolf, T., Tackley, P.J. and Labrosse, S. (2012), Dynamic Causes of the Relation Between Area and Age of the Ocean Floor, Science 336, 335-338.

Costello M.J., Cheung A., and De Hauwere N. (2010), Surface Area and the Seabed Area, Volume, Depth, Slope, and Topographic Variation for the World's Seas, Oceans, and Countries, Environmental Science \& Technology 44, 8821-8828.

Crosby, A.G., McKenzie, D., and Sclater, J.G. (2006), The relationship between depth, age and gravity in the oceans, Geophysical Journal International 166, 553-573.

Crosby, A.G., McKenzie, D. (2009), An analysis of young ocean depth, gravity and global residual topography, Geophysical Journal International 178, 1198-1219.

Divins D.L. (2003), Total Sediment Thickness of the World's Oceans \& Marginal Seas, NOAA National Geophysical Data Center, Boulder, CO.

GALER, S.J.G. (1991), Interrelationships between continental freeboard, tectonics and mantle temperature, Earth and Planetary Science Letters 105, 214-228.

Galer, S.J.G., and MezGer, K. (1998), Metamorphism, denudation and sea level in the Archean and cooling of the Earth, Precambrian Research 92, 389-412.

Goutorbe, B. and HiLlier J.K. (2013), An integration to optimally constrain the thermal structure of oceanic lithosphere, Journal of Geophysical Research, Solid Earth 118, 432-446.

HaLL, J.K. (2006), GEBCO Centennial Special Issue - Charting the secret world of the ocean floor: the GEBCO project 1903-2003, Marine Geophysical Researches 27, 1-5.

Harrison, C.G.A., Miskell, K.J., Brass, G.W., Saltzman, E.S., and SLOAN, J.L. II (1983), Continental hypsography, Tectonics 2, 357-378.

HasteroK, D., (2013), Global patterns and vigor of ventilated hydrothermal circulation through young seafloor, Earth and Planetary Science Letters 380, 12-20.

HillieR, J.K., and WATTS, A.B. (2005), Relationship between depth and age in the North Pacific Ocean, Journal of Geophysical Research 110, B02405.

HilLIER, J.K. (2010), Subsidence of "normal" seafloor: Observations do indicate "flattening", Journal of Geophysical Research, Solid Earth 115, B03102, DOI: 10.1029/2008JB005994.
Houtz, R.E., Hayes, D.E., and MARKL, R.G. (1977), Kerguelen Plateau bathymetry, sediment distribution and crustal structure, Marine Geology 25, 95-98, 101-130.

Johnson, H.P., and CARLson, R.L. (1992), Variation of sea floor depth with age: a test of models based on drilling results, Geophysical Research Letters 19(19), 1971-1974.

Korenaga, T., and Korenaga, J. (2008), Subsidence of normal oceanic lithosphere, apparent thermal expansivity, and seafloor flattening, Earth and Planetary Science Letters 268, 41-51.

Marks, K.M., and SмITH, H.F. (2006), An evaluation of publicly available global bathymetry grids, Marine Geophysical Researches 27, 19-34.

Menard, H.W., and Smith, S.M. (1966), Hypsometry of ocean basin provinces, Journal of Geophysical Research 71, 4305-4325.

Miller, K.G., Kominz, M.A., Browning, J.V., Wright, J.D., Mountain, G.S., Katz, M.E., Sugarman, P.J., Cramer, B.S., Christie-Blick, N., and Pekar, S.F. (2005), The Phanerozoic record of global sea-level change, Science 310, 1293-1298.

Mooney, W.D., Laske, G., and Guy Masters, T. (1998), CRUST 5.1: A global crustal model at $5^{\circ} \times 5^{\circ}$, Journal of Geophysical Research: Solid Earth 103, 727-747.

Murray, J., and Hjort, J. (1912), The Depths of the Ocean, 821 pp. Müller, R.D., Roest, W.R., Royer, J.-Y., Gahagan, L.M., and SClater, J.G. (1997), Digital isochrons of the world's ocean floor, Journal of Geophysical Research 102(B2), 3211-3214.

Müller, R.D., Sdrolias, M., Gaina, C., and Roest, W.R. (2008), Age, spreading rates and spreading symmetry of the world's ocean crust, Geochemistry, Geophysics, Geosystems 9, Q04006, doi:10.1029/2007GC001743.

Parsons, B., and Sclater, J.G. (1977), An analysis of the variation of ocean floor bathymetry and heat flow with age, Journal of Geophysical Research 82, 803-827.

PARsons, B. (1982), Causes and consequences of the relation between area and age of the ocean floor, Journal of Geophysical Research 87(B1), 289-302.

Rowley, D.B. (2002), Rate of plate creation and destruction: $180 \mathrm{Ma}$ to present, Geological Society of America Bulletin 114, 927-933.

Smith, W.H., and SAndwell, D.T. (1997), Global sea floor topography from satellite altimetry and ship depth soundings, Science 277, 1956-1962.

STEIN, C.A., and STEIN S. (1992), A model for the global variation in oceanic depth and heat flow with lithospheric age, Nature 359, 123-129.

STRAHLER, A.N. (1952), Hypsometric (area-altitude) analysis of erosional topography, Geological Society of America Bulletin $63,1117-1141$.

SYKES, T.J.S. (1996), A correction for sediment load upon the ocean floor: Uniform versus varying sediment density estimations implications for isostatic correction, Marine Geology 133, 35-49.

Tenzer, R., Novk, P., Gladkikh, V. (2011), On the accuracy of the bathymetry-generated gravitational field quantities for a depthdependent seawater density distribution, Studia Geophysica et Geodaetica 55, 609-626.

Yesson C., Clark M.R., Taylor M.L., and Rogers A.D. (2011), The global distribution of sea mounts based on 30 arc seconds bathymetry data, Deep-Sea Research I 58, 442-453. 